\title{
Effects of Different Basil Hydrosol Doses on the Germination and Shoot and Root Lenghts of Basil (Ocimum basilicum) and Quinoa (Chenopodium quinoa) Seeds
}

\author{
Mahmut ÇAMLICA ${ }^{1}$, Gülsüm YALDIZ1, Ferit ÖZEN² \\ ${ }^{1}$ Department of Field Crops, Faculty of Agriculture and Natural Sciences, Abant Izzet BaysalUniversity, 14280 Bolu, TURKEY \\ ${ }^{2}$ Mudurnu Süreyya Astarcı Vocational School, Medicinal and Aromatic Plants Department, 14800 Mudurnu Bolu, TURKEY
}

\begin{abstract}
Objective: Medicinal and aromatic plants (MAPs) have allelopathic effects on seed germination, root and shoot length due to the chemicals included in their extracts or essential oils. In this study, the changes in the germination rate, and shoot and root length of basil (Ocimum basilicum) and quinoa (Chenopodium quinoa) seeds exposed to different concentrations of basil hydrosol have been investigated. Material and Methods: The treatments included distilled water (control), tap water and different concentrations of basil hydrosol $(0.5,1,1.5$ and $2 \mathrm{ml})$. The study was conducted with a randomized complete block design with 3 replications. Twenty seeds of each species were placed on a filter paper in Petri dishes. For each treatment, $2 \mathrm{ml}$ test solution (distilled water or tap water or hydrosols) was applied to each replicate. All the experiments were carried out at $29 \pm 1{ }^{\circ} \mathrm{C}$, dark photoperiod using a drying oven under laboratory conditions. Results: All the basil and quinoa seeds were successfully germinated within 3 to 7 days. Following the treatments, the root and shoot lengths changed from 0.10 to $1.24 \mathrm{~cm}$ and 0.53 to $2.15 \mathrm{~cm}$, respectively for the basil and from 0.32 to $3.59 \mathrm{~cm}$ and 0.63 to $1.97 \mathrm{~cm}$ for the quinoa. Conclusion: Increasing the applied dosage of basil hydrosol significantly decreased the seed germination rate and shoot and root length. In particular, $2 \mathrm{ml}$ hydrosol prevented seed germination by more than $50 \%$ in basil.
\end{abstract}

Keywords: Hydrosol, Essential Oil, Quinoa, Basil, Germination, Shoot and Root Lengths.

\section{INTRODUCTION}

In agricultural farms, chemical herbicides are generally used to control weeds and decrease the harmful effects of insecticides. However, application of these chemicals has harmful side effects on the environment. Therefore, natural compounds are preferred to replace these chemicals to protect the environment. ${ }^{1}$ Many medicinal and aromatic plants have the potential to be used as a bio herbicide due their natural components constituting essential oil. Essential oils are obtained using different methods for their aromatic and volatile liquids extracted from plant materials. One of the simplest, oldest and primitive methods used for this purpose is hydro distillation, which is mostly preferred by small scale producers of essential oils.

In contrast to Essential oils, there has been only limited research on hydrosols, which are usually treated as waste products despite their extraordinary potential for use in in skin care, cosmetics, cooking and flavorings, and in medicine. ${ }^{2}$ They include a certain amount of essential oil molecules and they give solutions their scent and biological features. ${ }^{3,4,5}$ The plant species selected in this study, namely Ocimum basilicum (sweet basil) and Chenopodium quinoa (quinoa), are commonly used by local people for medicinal purposes or as a nutrient. The former is
DOI: 10.5530/ijper.51.3s.24

Correspondence:

Mahmut ÇAMLICA,

Department of Field Crops,

Faculty of Agriculture and

Natural Sciences, Abant

Izzet BaysalUniversity,

14280 Bolu, TURKEY

Contact: +90 37425343

45- 2673

E-mail: mcamlica25@

outlook.com

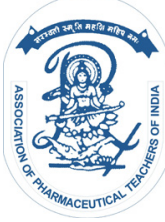

www.ijper.org 
used for the treatment of dry mouth and dental complaints, diarrhea, chronic dysentery, and respiratory disorders. It is also effective in the treatment of fungal diseases and stomach discomfort and plays a significant role in medicine with its antitussive, diuretic, anthelminthic, tranquilizer and expectorant properties. ${ }^{67}$ Quinoa is native food plant of high nutritional value grown in the Andean region used as a food for humans and animals dating back to the Incas and earlier cultures. ${ }^{8}$

This study investigated the effects of hydrosol obtained from basil on the seed germination and shoot and root length of Ocimum basilicum and Chenopodium quinoa.

\section{MATERIAL AND METHOD}

\section{Plant materials and extraction}

Hydrosols of basil (Ocimum basilicum leaves) were prepared by the hydro distillation method using a Neo Clevenger-type apparatus. The plant materials were collected in a field experiment and quinoa seeds were obtained from a farmer in 2016. After grinding $15 \mathrm{~g}$ samples, the hydrosol was prepared was extracted by hydro distillation for $3 \mathrm{~h} .50 \mathrm{ml}$ hydrosol was collected over the 3-hour period and placed in flasks to be kept in refrigerator until use.

\section{Seed germination and shoot and root length}

From each species of Ocimum basilicum and Chenopodium quinoa, 20 seeds were placed on filter paper in Petri dishes to be germinated. For both species, six treatment groups each having three Petri dishes were formed as follows: Control (only pure water), tap water, $0.5 \mathrm{ml}$ hydrosol and $1.5 \mathrm{ml}$ pure water, $1 \mathrm{ml}$ hydrosol and $1 \mathrm{ml}$ pure water, $1.5 \mathrm{ml}$ hydrosol and $0.5 \mathrm{ml}$ pure water, and $2 \mathrm{ml}$ hydrosol. Thus, each Petri dish contained $2 \mathrm{ml}$ solution. Hydrosol was applied to the plants for 15 days and the germination rates (number germinated seeds/ day) and root and shoot lengths ( $\mathrm{cm}$ ) were determined.

\section{Statistical analysis}

This study was organized in a completely randomized design. Statistical evaluation was performed using SPSS version 23 and the means were compared by Duncan's multiple range test as a post-hoc analysis.

\section{RESULT AND DISCUSSION}

Hydrosol extracted from basil was applied to the basil and quinoa samples. The seeds were germinated within 3 to 7 days. When germination stopped (after 15 days), the plants were assessed in terms of shoot and root lengths. According to the results, basil hydrosol had a greater effect on the germination of basil plant compared to quinoa. Furthermore, basil hydrosol had a significantly higher effect on the germination of basil and quinoa plant compared to tap and distilled water treatments.

\section{Number of germination seed and germination percentage}

The germination of 2 plant seeds was significantly inhibited by all doses of basil hydrosol. The maximum germination was observed in the control and tap water groups, followed by $0.5 \mathrm{ml}$ hydrosol, and the minimum germination was seen in $2 \mathrm{ml}$ hydrosol treatment for both plant materials (Table 1). At $2 \mathrm{ml}$ hydrosol, basil seeds showed more reduction in germination rate compared to quinoa seeds. The seeds of basil and quinoa were successfully germinated at all hydrosol doses, but their germination was more inhibited compared to the control group. Table 1 presents the reduction in the germination percentage by hydrosol dose.

\section{Shoot length}

Concerning the results on shoot length (Table 2), as the hydrosol concentration increased, the shoot length generally decreased except the $1.5 \mathrm{ml}$ hydrosol application in quinoa. The shoot length of both basil and quinoa samples differed depending on the treatment they received and was in the following descending order: tap water $>$ control $>0.5 \mathrm{ml}$ hydrosol $>1.0 \mathrm{ml}$ hydrosol

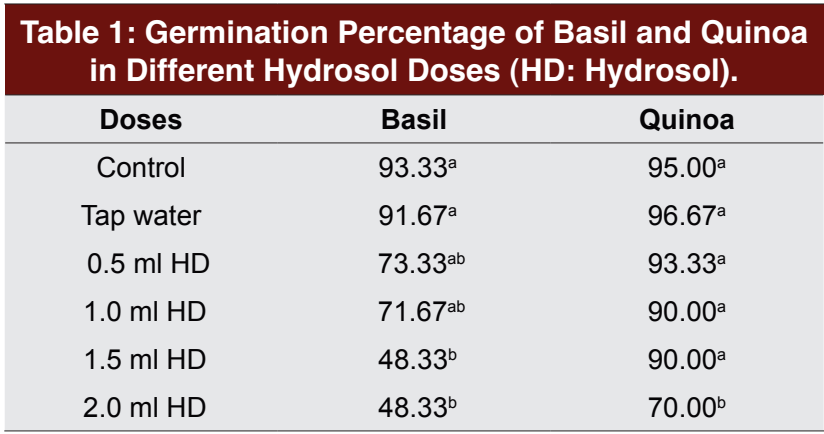

Different letters at each column indicate significant differences at $5 \%$ probability level by Duncan's multiple range test

Table 2: Shoot Lenght of Basil and Quinoa in Different Hydrosol Doses (HD: Hydrosol).

\begin{tabular}{|c|c|c|}
\hline Doses & Basil & Quinoa \\
\hline Control & $1.83^{\mathrm{a}}$ & $1.80^{\mathrm{ab}}$ \\
\hline Tap water & $2.15^{\mathrm{a}}$ & $1.85^{\mathrm{a}}$ \\
\hline $0.5 \mathrm{ml} \mathrm{HD}$ & $1.64^{\mathrm{a}}$ & $1.97^{\mathrm{a}}$ \\
\hline $1.0 \mathrm{ml} \mathrm{HD}$ & $1.57^{\mathrm{a}}$ & $1.43^{\mathrm{ab}}$ \\
\hline $1.5 \mathrm{ml} \mathrm{HD}$ & $0.69^{\mathrm{b}}$ & $1.13^{\mathrm{ab}}$ \\
\hline $2.0 \mathrm{ml} \mathrm{HD}$ & $0.53^{\mathrm{b}}$ & $0.63^{\mathrm{b}}$ \\
\hline
\end{tabular}

Different letters at each column indicate significant differences at $5 \%$ probability level by Duncan's multiple range test 


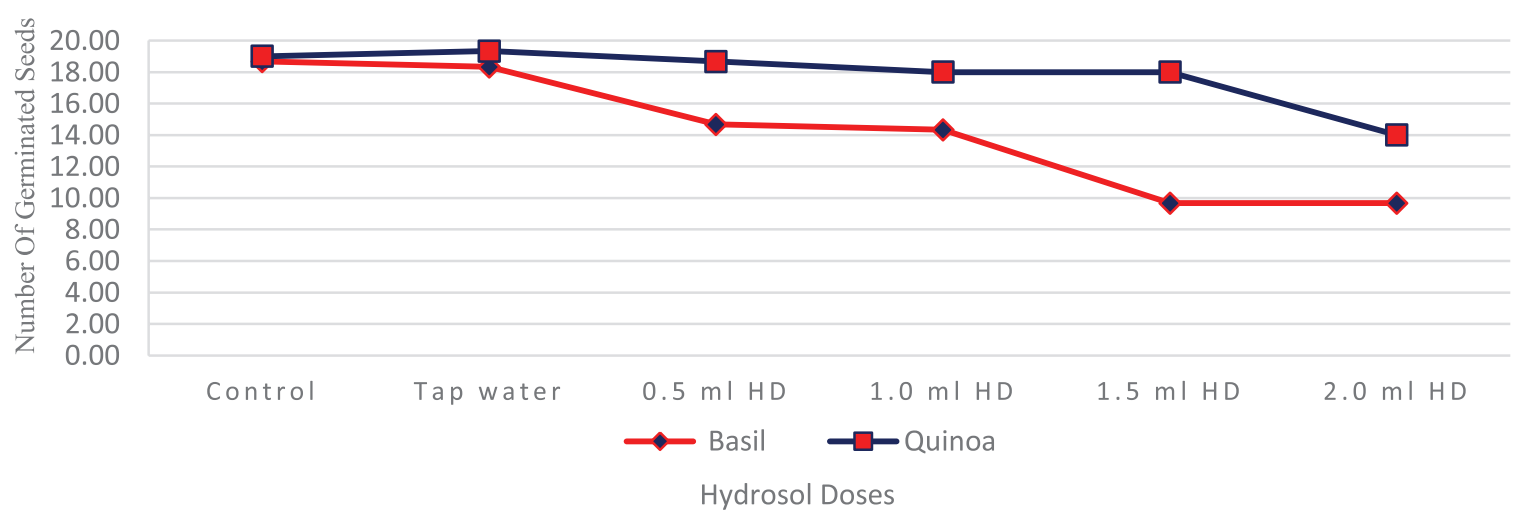

Figure 1: The effects of the different hydrosol concentrations on seed germination (HD: Hydrosol).

$>1.5 \mathrm{ml}$ hydrosol $>2 \mathrm{ml}$ hydrosol. The highest reduction in the shoot length $(0.53 \mathrm{~cm})$ was obtained from the $2 \mathrm{ml}$ hydrosol concentration in quinoa and the longest shoots were observed following control treatments both in basil $(2.15 \mathrm{~cm})$ and quinoa $(2.40 \mathrm{~cm})$. Considering different hydrosol concentrations, the highest germination rate was obtained from quinoa at $0.5 \mathrm{ml}$ and the lowest value was determined from basil at 1.5 and $2 \mathrm{ml}$.

\section{Root lenght}

Table 3 shows the impact of basil hydrosol on the root length of the plant samples. With the increasing dose of hydrosol, the root length significantly decreased. For basil, the longest root was achieved at $1.25 \mathrm{~cm}$ following the control application and the shortest root was $0.10 \mathrm{~cm}$, which was obtained from the $2 \mathrm{ml}$ hydrosol treatment. Quinoa was found to be more resistant to hydrosol and had a longer root length $(0.32 \mathrm{~cm})$ than basil after the application of the highest hydrosol dose. The root length of the plants was obtained in the following order depending on the treatment: tap water $>$ control $>0.5 \mathrm{ml}$ hydrosol $>1.0 \mathrm{ml}$ hydrosol $>1.5 \mathrm{ml}$ hydrosol $>2 \mathrm{ml}$ hydrosol for basil and tap water $>$ control $>0.5$ hydrosol $>1.5$ hydrosol $>1.0$ hydrosol $>$ hydrosol 2 for quinoa.

\begin{tabular}{ccc}
$\begin{array}{r}\text { Table 3: Root Lenght of Basil and Quinoa in Different } \\
\text { Hydrosol Doses (HD: Hydrosol). }\end{array}$ \\
\hline Doses & Basil & Quinoa \\
\hline Control & $1.24^{\mathrm{a}}$ & $3.59^{\mathrm{a}}$ \\
Tap water & $0.97^{\mathrm{ab}}$ & $2.64^{\mathrm{ab}}$ \\
$0.5 \mathrm{ml} \mathrm{HD}$ & $0.90^{\mathrm{ab}}$ & $2.49^{\mathrm{ab}}$ \\
$1.0 \mathrm{ml} \mathrm{HD}$ & $0.77^{\mathrm{b}}$ & $1.27^{\mathrm{bc}}$ \\
$1.5 \mathrm{ml} \mathrm{HD}$ & $0.36^{\mathrm{c}}$ & $1.22^{\mathrm{bc}}$ \\
$2.0 \mathrm{ml} \mathrm{HD}$ & $0.10^{\mathrm{c}}$ & $0.32^{\mathrm{c}}$ \\
\hline
\end{tabular}

Different letters at each column indicate significant differences at $5 \%$ probability level by Duncan's multiple range test
In the literature, researchers have reported that the growth of wheat, maize, and cotton is much less affected by the hydrosol of Ipomea carnea leaves than water and cotton is also not significantly affected by the hydrosol of other plant materials such as Ipomea carnea flowers and Lantana carnea leaves). ${ }^{9}$ It has also been determined that extracts obtained from rhizomes with roots and aerial part of Angelica L. species Angelica archangelica influence the seed germination and initial plant growth of Linum usitatissimum L., Raphanus sativus L., Cucumis sativus L., and Brassica oleracea L. ${ }^{10}$

\section{CONCLUSION}

A notable finding of the present study is that hydrosol significantly inhibited the germination of the two plant species under laboratory conditions. The germination rates and shoot and root lengths of both plant species were found to be lower following hydrosol applications compared to tap and distilled water treatments. Furthermore, when the results of hydrosol applications were compared, the minimum values were obtained from the highest concentration $(2 \mathrm{ml})$ and the maximum values were observed in the lowest concentration $(0.5 \mathrm{ml})$. Lastly, in all hydrosol treatments, the results obtained from quinoa were better compared to basil; therefore, it can be concluded that quinoa is more resistant to basil hydrosol.

\section{ACKNOWLEDGEMENT}

Nil

\section{CONFLICT OF INTEREST}

\section{Nil}




\section{ABBREVIATIONS USED}

h: Hour; SPSS: Statistical Package for the Social Science; HD: Hydrosol.

\section{REFERENCES}

1. Shokouhian A, Habibi H, Agahi K. Allelopatic effects of some medicinal plant essential oils on plant seeds germination. Journal of Bio Science and Biotechnology. 2016;5(1):13-7.

2. Aazza I, Lyoussi B, Miguel MG. Antioxidant activity of eight hydrosols from Morocco. Asian Journal of Plant Sciences. 2012;11(3):137-42.

3. Rose J, Earle S. The world of aromatherapy. Berkeley, Frog Ltd; 1996.

4. Lis-Balchin M. Aromatherapy science. Pharmaceutical press; 2006.

5. Catty S. 1. Hydrosols, the next aromatherapy. Healing Arts Press, Rochester Vermont; 2001.
6. Keita SM, Vincent C, Schmit J, Arnason JT, Belanger A. Efficacy of essential oil of Ocimum basilicum L. and Ocimum gratissimum L. applied as an insecticidal fumigant and powder to control Callosobruchus maculatus (Fab.). Journal of Stored Products Research. 2001;37(4):339-49.

7. Telci I, Bayram E, Yilmaz G, Avci B. Variability in essential oil composition of Turkish basils (Ocimum basilicum L.). Biochemical Systematic and Ecology. 2006;34(6):489-97.

8. Tan M, Yöndem Z. İnsan ve hayvan beslenmesinde yeni bir bitki: Kinoa (Chenopodium quinoa Willd.). Alınteri Zirai Bilimler Dergisi. 2013;25(2): 62-6.

9. Suradkar VB, Wankhade BB, Talreja RG, Talreja MS, Ochani PD. Effect of hydrosol of Ipomea carnea leaves, flowers and Lantana camera leaves on the growth of wheat, maize and cotton plant. International Journal of Pharmaceutical Sciences and Research. 2016;7(8):3477-9.

10. Lobiuc A, Olteanu Z, Stratu A, Cojocaru DD, Zamfırache MM. The effect of some Angelica L. sp. hydrosols on seed germination and initial plant growth. Carpathian Journal of Earth and Environmental Sciences. 2014;9(1):133-40.

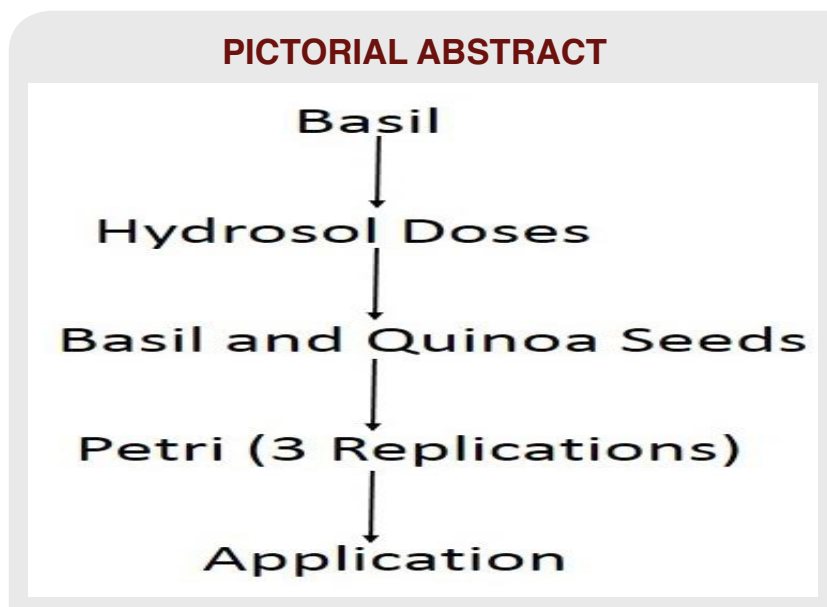

\section{SUMMARY}

- All basil hydrosol doses significantly inhibited the germination rates and shoot and root length of both plant species.

- There was a gradual decrease in the germination rates and shoot and root lengths with rising doses of basil hydrosol doses.

- The highest doses $(2 \mathrm{ml}$ ) have shown low germination rates and shoot and root lengths of both plant species.

- The quinoa seeds are rather resistant to basil hydrosol compared to the basil seeds.

\section{ABOUT AUTHORS}

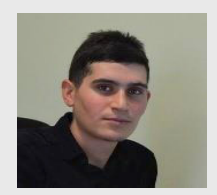

Mahmut Çamlica: He is presently working as research assistant at the Department of Medicinal and Aromatic Plants, Faculty of Agriculture and Natural Sciences in Abant Izzet Baysal University. His studies mainly focused on the natural medicinal and aromatic plant product.

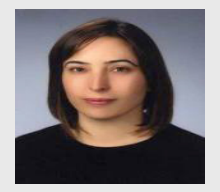

Gülsüm Yaldiz: She graduated from Faculty of Agriculture in Cukurova University and get BS degree in 2001. She obtained her Ph.D. degree in 2008 from Department of Field Crop, Cukurova University. She is positioned as Assistant Professor, Department of Field Crops, Faculty of Agriculture and Natural Sciences in Abant Izzet Baysal University. Her mainly subjects of interest are good agricultural practices, natural medicinal product, biological and chemical properties of plants

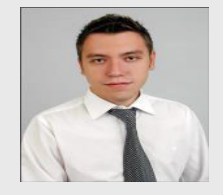

Ferit Özen: He is presently working as lecturer at Programme of Medicinal and Aromatic Plants, Department of Crop and Animal Production in Abant Izzet Baysal University Mudurnu Sureyya Astarci Vocational School. He has given courses about medicinal and aromatic plants breeding and growing.

Cite this article: ÇAMLICA M, YALDIZ G, ÖZEN F. Effects of Different Basil Hydrosol Doses on the Germination and Shoot and Root Lenghts of Basil (Ocimum basilicum) and Quinoa (Chenopodium quinoa) Seeds. Indian $\mathrm{J}$ of Pharmaceutical Education and Research. 2017;51(3)Suppl:S254-57. 